\title{
What do satellite backscatter ultraviolet and visible spectrometers see over snow and ice? A study of clouds and ozone using the A-train
}

\author{
A. P. Vasilkov ${ }^{1}$, J. Joiner ${ }^{2}$, D. Haffner ${ }^{1}$, P. K. Bhartia ${ }^{2}$, and R. J. D. Spurr ${ }^{3}$ \\ ${ }^{1}$ Science Systems and Applications Inc., Lanham, MD, USA \\ ${ }^{2}$ Goddard Space Flight Center, Laboratory for Atmospheres, Greenbelt, MD, USA \\ ${ }^{3}$ RT Solutions, Cambridge, MA, USA
}

Received: 14 December 2009 - Published in Atmos. Meas. Tech. Discuss.: 26 January 2010

Revised: 20 April 2010 - Accepted: 5 May 2010 - Published: 18 May 2010

\begin{abstract}
In this paper, we examine how clouds over snow and ice affect ozone absorption and how these effects may be accounted for in satellite retrieval algorithms. Over snow and ice, the Aura Ozone Monitoring Instrument (OMI) Raman cloud pressure algorithm derives an effective scene pressure. When this scene pressure differs appreciably from the surface pressure, the difference is assumed to be caused by a cloud that is shielding atmospheric absorption and scattering below cloud-top from satellite view. A pressure difference of $100 \mathrm{hPa}$ is used as a crude threshold for the detection of clouds that significantly shield tropospheric ozone absorption. Combining the OMI effective scene pressure and the Aqua MODerate-resolution Imaging Spectroradiometer (MODIS) cloud top pressure, we can distinguish between shielding and non-shielding clouds.

To evaluate this approach, we performed radiative transfer simulations under various observing conditions. Using cloud vertical extinction profiles from the CloudSat Cloud Profiling Radar (CPR), we find that clouds over a bright surface can produce significant shielding (i.e., a reduction in the sensitivity of the top-of-the-atmosphere radiance to ozone absorption below the clouds). The amount of shielding provided by clouds depends upon the geometry (solar and satellite zenith angles) and the surface albedo as well as cloud optical thickness. We also use CloudSat observations to qualitatively evaluate our approach. The CloudSat, Aqua, and Aura satellites fly in an afternoon polar orbit constellation with ground overpass times within 15 min of each other.
\end{abstract}

Correspondence to: A. P. Vasilkov (alexander_vassilkov@ssaihq.com)
The current Total Ozone Mapping Spectrometer (TOMS) total column ozone algorithm (that has also been applied to the OMI) assumes no clouds over snow and ice. This assumption leads to errors in the retrieved ozone column. We show that the use of OMI effective scene pressures over snow and ice reduces these errors and leads to a more homogeneous spatial distribution of the retrieved total ozone.

\section{Introduction}

According to the review by Curry et al. (1996), the radiation budget for snow-covered regions depends significantly on the presence of clouds. This dependence is not well understood, mostly owing to a lack of reliable cloud data over these areas. Since then, a number of algorithms have been developed for satellite detection of clouds over snow and ice (e.g., Ackerman et al., 1998; Gao et al., 1998; Key et al., 2001; Pinker et al., 2007; Wang and Key, 2003; Li et al., 2007; Khlopenkov and Trishchenko, 2007).

For most surface types, threshold techniques based on cloud spectral constrasts in the visible and thermal infrared (IR) are sufficiently reliable to detect clouds. These thresholds are based on the fact that clouds are usually brighter and colder than the surface. However, they have difficulty discriminating between clouds and snow- and ice-covered surfaces, because these surfaces can be as bright and cold as the overlying cloud (Gao et al., 1998). In fact, snow/ice surfaces are sometimes colder than overlying clouds, due to temperature inversions that are common in the polar regions (Curry et al., 1996). 
Gao et al. (1998) demonstrated that the $1.38 \mu \mathrm{m}$ water vapor absorption channel on the MODerate-resolution Imaging Spectroradiometer (MODIS) is useful for detecting high clouds over snow and ice during the daytime. They also showed that lower-level water-droplet clouds can be distinguished from background snow and ice using a channel located at the center of the $1.5 \mu \mathrm{m}$ ice absorption band.

Ackerman et al. (1998) developed the operational MODIS cloud mask algorithm that includes detection of clouds over snow and ice. The algorithm uses a combination of several spectral threshold tests in the visible, near IR, and thermal IR. Again, the reflectance channel at $1.38 \mu \mathrm{m}$ is used for detection of high clouds over snow and ice. More details can be found in Ackerman et al. (2006).

Spectral threshold tests are also used for detecting clouds over snow and ice with the Advanced Very High Resolution Radiometer (AVHRR) (Key, 2002). Cloud detection and optical depth retrievals with AVHRR utilize reflectances at 0.9 and $3.7 \mu \mathrm{m}$ as well as differences in brightness temperatures at 11 and $12 \mu \mathrm{m}$. The algorithm was applied to the 17-year AVHRR record over the Arctic to study trends in cloud coverage and short-wave cloud radiative forcing (Wang and Key, 2003). Key et al. (2001) demonstrated that satellite monitoring of the temporal and spatial variability of broadband surface albedo can also be accomplished with this data record. They concluded that on average, the snow/ice albedo is approximately 0.04 to 0.06 higher under cloud cover than for clear skies.

Li et al. (2007) suggested a new coupled cloud and snow detection algorithm applicable to the Geostationary Operational Environmental Satellites (GOES) imager. The algorithm was designed to improve satellite estimates of shortwave radiative fluxes for snow covered areas (Pinker et al., 2007).

Krijger et al. (2005) developed an algorithm to differentiate between clouds and snow/ice covered surfaces that makes use of the SCanning Imaging Absorption spectroMeter for Atmospheric CHartographY (SCIAMACHY) polarization measurement device (PMD) observations in the spectral range between $450 \mathrm{~nm}$ and $1.6 \mu \mathrm{m}$. The algorithm is based on spectral threshold tests and mostly utilizes the difference in reflectance between clouds and the snow covered surface around $1.6 \mu \mathrm{m}$. A similar algorithm was used by Lotz et al. (2009).

In clear-sky conditions, satellite backscatter ultraviolet (UV) and visible (Vis) instruments have enhanced sensitivity to trace-gas absorbers in the lower troposphere over snow and ice as compared with lower albedo surfaces. However, clouds screen absorption and reduce this sensitivity enhancement over snow and ice. Therefore, knowledge of cloud properties is important for accurate retrieval of tropospheric trace gas amounts from UV/Vis sensors over snow and ice. Relevant trace gases include $\mathrm{O}_{3}, \mathrm{NO}_{2}, \mathrm{BrO}$, and $\mathrm{SO}_{2}$. The importance of cloud height information for trace- gas retrievals in general has been documented (e.g., Koelemeijer et al., 1999; Vasilkov et al., 2004).

There are several satellite UV/Vis backscatter spectrometers that currently provide trace-gas and cloud height information. These include SCIAMACHY (Bovensmann et al., 1999) on the European Space Agency (ESA) Environmental Satellite (EnviSat) launched in 2002, the Ozone Monitoring Instrument (OMI) (Levelt et al., 2006) flying on the National Aeronautics and Space Administration (NASA) Aura satellite since 2004, the Global Ozone Monitoring Experiment (GOME) on the European Space Agency (ESA) European Remote Sensing satellite 2 (ERS-2) launched in 1995 (Burrows et al., 1999), and GOME-2 (Munro et al., 2006) launched on the EuMetSat MetOp platform in late 2006.

Over snow and ice, the OMI rotational-Raman cloud pressure algorithm derives an effective scene pressure assuming a Lambertian surface. In clear-sky conditions, this scene pressure should be equal to the surface pressure. The shielding effect of clouds lowers the retrieved scene pressure and also reduces the amount of tropospheric ozone seen by the satellite. The current OMI total ozone algorithm, based on the heritage Total Ozone Mapping Spectrometer (TOMS) algorithm, does not account for the effects of clouds over snow and ice (Bhartia and Wellemeyer, 2002).

Various Differential Optical Absorption Spectroscopy (DOAS) ozone algorithms applied to GOME and SCIAMACHY (Coldewey-Egbers et al., 2005; Roozendael et al., 2006) make use of cloud information from the oxygen Aband (Koelemeijer et al., 2001; Kokanovsky et al., 2006). For example, over snow and ice the oxygen A-band cloud algorithm of Koelemeijer et al. (2001) assumes full cloud coverage and retrieve the effective scene height which comes out as a height of a Lambertian reflecting layer that provides the observed amount of oxygen absorption. This effective scene height is then used for estimating the ghost vertical column of ozone to be added to the total column ozone (ColdeweyEgbers et al., 2005). It should be noted that OMI does not provide measurements in the oxygen A-band.

Here, we investigate whether the use of retrieved OMI scene pressures over snow and ice can improve total column ozone retrievals. We use a radiative transfer model in conjunction with profiles of cloud extinction from the CloudSat and Aqua MODIS instruments to examine how the cloud shielding effect varies with solar and satellite geometry as well as surface and cloud properties. We also propose a relatively simple scheme for the OMI and MODIS sensors to classify clouds as either shielding or non-shielding over snow and ice. All three instruments are part of the so-called Atrain polar-orbiting satellite constellation; collocated measurements are taken within a 15-min time span. The CloudSat radar data provide an excellent opportunity to evaluate this OMI/MODIS classification.

The paper is structured as follows. Section 2 briefly describes the OMI cloud pressure algorithm that is based on atmospheric rotational-Raman scattering. Section 3 presents 
radiative transfer simulations for a simple cloud model to study the effects of a bright underlying surface on the derived scene reflectivity, scene pressure, and column ozone. In Sect. 4, we use the OMI-retrieved scene pressure to classify clouds over snow/ice. Results are qualitatively compared with CloudSat data. In Sect. 5, we compare OMI total column ozone retrievals over snow and ice derived with the assumption of no clouds and with OMI-derived scene pressures. Conclusions are given in Sect. 6.

\section{Optical centroid pressure (OCP) from OMI}

OMI is a nadir-viewing radiometer that measures the solar irradiance and Earth backscattered radiance from 270 to $500 \mathrm{~nm}$ (Levelt et al., 2006). It provides near-global coverage with a nadir pixel size of 13 by $24 \mathrm{~km}$ in the UV-2 channel (310-365 nm) used to retrieve total column ozone.

In this paper, we use scene pressures retrieved from OMI with an algorithm based on atmospheric rotational-Raman scattering (RRS) in the UV-2 channel (Joiner et al., 2004; Joiner and Vasilkov, 2006). The RRS algorithm uses a fitting window of $346-354 \mathrm{~nm}$ that has an average spectral sampling distance of $0.15 \mathrm{~nm}$ and a full-width half-maximum (FWHM) slit of $0.45 \mathrm{~nm}$. The OMI-RRS algorithm retrieves a cloud pressure, referred to here as the optical centroid pressure (OCP), from the measured amount of filling-in and depletion of solar Fraunhofer lines, also known as the Ring effect, produced by RRS. The filling-in effect generates a highfrequency structure in the top-of-the-atmosphere (TOA) radiance spectrum. The OCP is derived by a minimumvariance technique that spectrally fits the observed highfrequency structure of TOA reflectance. In general, screening of the lower atmosphere by clouds reduces the amount of Fraunhofer-line filling-in seen by satellite instruments.

The OMI-RRS OCPs are qualitatively similar to those derived from algorithms based on oxygen dimer $\left(\mathrm{O}_{2}-\mathrm{O}_{2}\right)$ and oxygen A-band absorption (Sneep et al., 2008) in the visible and near IR, respectively. However, our OCPs differ considerably from cloud-top pressures retrieved from thermal infrared (IR) observations (Vasilkov et al., 2008; Joiner et al., 2010).

By computing ozone absorption Jacobians inside convective clouds, Ziemke et al. (2008) demonstrated that photons penetrate deeply inside these clouds, reaching pressures near the OCP value with enhanced ozone absorption due to multiple scattering in the upper portions of such clouds. This provides strong evidence that the OCP is more appropriate than cloud-top pressure for radiative calculations in the visible and ultraviolet. Joiner et al. (2009) subsequently used the OCP for accurate satellite-derived estimates of the tropospheric ozone impact on the global radiation budget. Similarly, Vasilkov et al. (2009) used the OCP for estimates of the tropospheric $\mathrm{NO}_{2}$ impact on the regional radiation budget. The OCP has also been used to estimate ozone mixing ratios inside deep convective clouds given an estimate of the ozone column above the clouds (Ziemke et al., 2008).

For OMI, snow- and ice-covered surfaces are flagged using the Near Real-time SSM/I EASE-Grid Daily Global Ice Concentration and Snow Extent (NISE) data set (Nolin et al., 1998). In these conditions, the OMI RRS cloud pressure algorithm retrieves an effective scene pressure, $P_{\text {scene, }}$ assuming a Lambertian surface. $P_{\text {scene }}$ is defined for a given pixel as the pressure at which a Lambertian surface must be placed in order to produce the observed amount of rotational-Raman scattering. In this Lambertial model, the surface albedo is set equal to the LER (Lambert-Equivalent Reflectivity) $R$ at $354 \mathrm{~nm}$; RRS filling effects are small at this wavelength. The LER is defined by

$I_{\mathrm{m}}=I_{0}+R I_{g} \gamma /\left(1-R S_{\mathrm{b}}\right)$,

where $I_{\mathrm{m}}$ is the measured TOA radiance, $I_{0}$ is the TOA radiance calculated for a pure Rayleigh atmosphere and surface reflectivity $R=0, I_{g}$ is the total irradiance reaching the surface, $\gamma$ is the the transmittance of the radiance reflected from the surface, and $S_{\mathrm{b}}$ is the fraction of the reflected surface flux that is scattered by the atmosphere back to the surface.

$P_{\text {scene }}$ is derived from the measured RRS filling-in using a lookup table approach. The cloud screening effect will cause $P_{\text {scene }}$ to differ from the surface pressure, $P_{\text {surf }}$. When the difference $\Delta P=P_{\text {surf }}-P_{\text {scene }}$ is small, either no cloud is present or a cloud is not generating significant shielding.

Figure 1 shows examples of $\Delta P$ for three OMI scan lines over Antarctica. The surface pressure here is computed from a $0.5^{\circ} \times 0.5^{\circ}$ terrain-height data set using the standard atmosphere. $\Delta P$ is small $(<25 \mathrm{hPa})$ or even slightly negative for OMI scan lines 300 and 350 . However, $\Delta P$ exceeds $200 \mathrm{hPa}$ for OMI scan line 400. This is presumably due to the presence of shielding clouds. Collocated Aqua MODIS cloud retrievals (Platnick et al., 2001) confirm the presence of clouds with optical thickness $(\tau)$ greater than 20 over this part of Antarctica.

In general, the shielding effect of clouds reduces the filling-in. However, under some circumstances, the presence of clouds with an underlying bright surface can increase filling-in and ozone absorption as compared with clear-sky conditions. This is due to light that penetrates through an optically thin cloud and undergoes enhanced scattering between the cloud and bright surface (Vasilkov et al., 2008). This photon trapping effect has been well established in the literature (e.g., Michelangeli et al., 1992; Rozanov et al., 2004a,b). The effect can lead to higher retrieved scene pressures for optically thin clouds $(\tau<1-8)$ over snow and ice as compared with values of $P_{\text {scene }}$ for a dark surface. The effect is most pronounced for low and moderate solar and view zenith angles. For large zenith angles, the photon trapping effect is diminished owing to large pathlengths through the cloud and atmosphere (e.g., large Rayleigh optical thickness especially at ultraviolet wavelengths). 

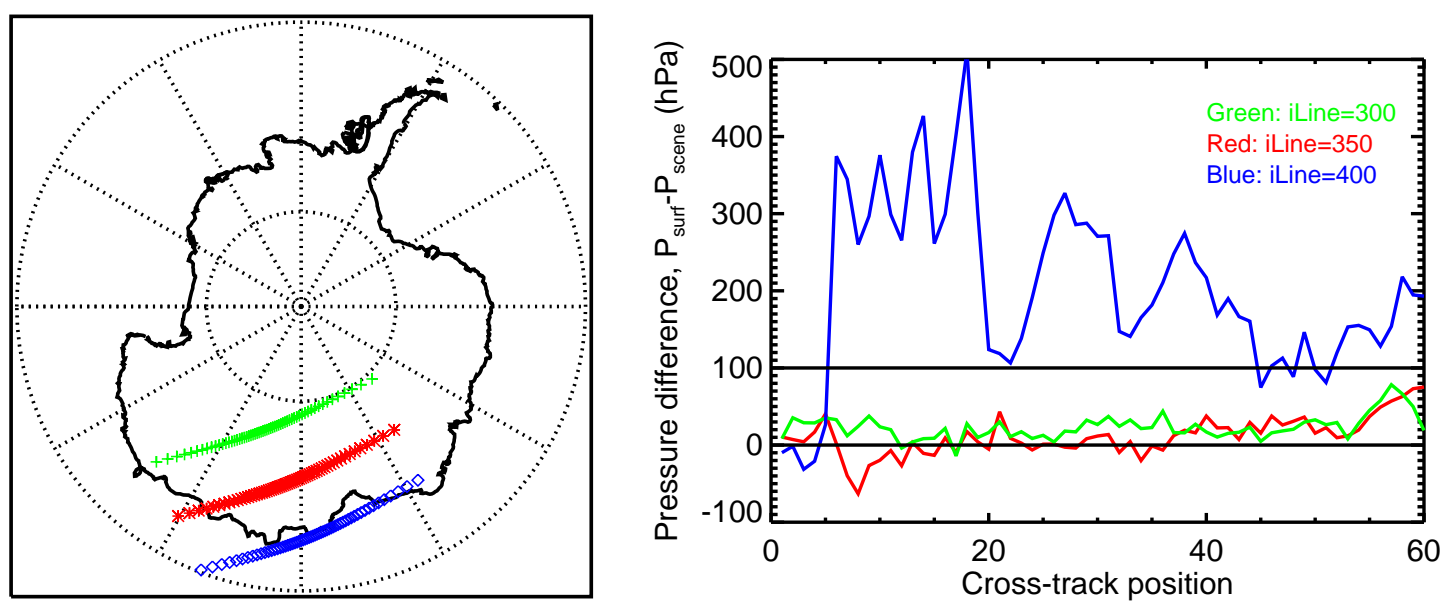

Fig. 1. Left: three OMI scan lines (iLine $=300,350$, and 400) over Antarctica for OMI orbit 12394 on 13 November 2006. Right: difference between surface pressure, $P_{\text {surf }}$, and retrieved scene pressure, $P_{\text {scene, }}$, (pressure of a Lambertian surface that provides the observed amount of rotational-Raman scattering - see text for details) for these scan lines as a function of OMI cross-track position.

\section{Radiative transfer simulations of cloud over snow/ice}

In this section, radiative transfer (RT) simulations are carried out using the generic discrete ordinate LIDORT-RRS code that accounts for RRS in the first-order approximation (Spurr et al., 2008). The RT code computes both the elastic and inelastic components of the radiance field in a multiplyscattering atmosphere. All simulations are based on the wavelength grid of the OMI-measured solar spectrum, with these irradiance values providing the input Fraunhofer structure. We next describe two sets of computations carried out with this code.

\subsection{Cloud pressures from simulated inelastic scattering}

In the first set of simulations, we create synthetic OMI radiances and then use them to retrieve cloud pressures with precomputed lookup tables. Synthetic radiances are computed for scenarios along the OMI scan line 300 on 13 November 2006 (see Fig. 1). The purpose of this exercise is to study how the cloud pressure retrievals depend upon input optical properties and viewing geometry for high solar zenith angles and high surface albedos.

We simulate radiances using plane-parallel clouds of $1 \mathrm{~km}$ geometric thickness with various values of cloud optical thickness $\tau$, cloud heights of 3 and $5 \mathrm{~km}$, and with three different cloud phase functions. The first of these is the waterdroplet $\mathrm{C} 1$ cloud model with a modified-gamma size distribution of equivalent radius of $6 \mu \mathrm{m}$ (Deirmendjian, 1969). The second is a Henyey-Greenstein (H-G) phase function with asymmetry factor $g=0.85$. Third, we use a shortwave model of ice cloud from http://www.ssec.wisc.edu/ $\sim$ baum/Cirrus/IceCloudModels.html with effective diameter of $30 \mu \mathrm{m}$ (Baum et al., 2005). In all cases, the cloud single scattering albedo is set to unity.

The surface is assumed to be Lambertian with an albedo of 0.7 or 0.9 and a pressure of $1013 \mathrm{hPa}$. We neglect the bidirectional reflectance distribution function (BRDF) of snow surfaces. The BRDF effect is smaller in the UV than in the visible; strong Rayleigh scattering in the UV smooths the BRDF effect. Li et al. (2007) investigated BRDF corrections to the LER for MODIS albedo retrieval over snow surfaces. At $412 \mathrm{~nm}$, the correction is less than $4 \%$ for all albedos.

We retrieve cloud pressure from synthetic radiances using a simplified version of the OMI RRS cloud algorithm. Instead of fitting multiple Fraunhofer features within the $345.5-354.5 \mathrm{~nm}$ fitting window normally used in the OMI $\mathrm{RR}$ algorithm, we use a single wavelength $(352.6 \mathrm{~nm})$. Details of this approach can be found in Vasilkov et al. (2008).

Figure 2 shows $\Delta P$, the simulated difference between the surface and retrieved scene pressure, as a function of $\tau$ for an OMI nadir view (solar zenith angle $\theta_{0}=66.7^{\circ}$ ) and for a swath edge view $\left(\theta_{0}=61.3^{\circ}\right.$, view zenith angle $\theta=69.7^{\circ}$, azimuth angle $\phi=66.8^{\circ}$ ) with a surface albedo of 0.7. Calculations are performed with the ice cloud model. $\Delta P \geq 100 \mathrm{hPa}$ is used here as a threshold for unambiguous detection of shielding clouds. This threshold is indicated in Fig. 2. At the swath edge, where the geometrical airmass factor $\left(\sec \left(\theta_{0}\right)+\sec (\theta)\right)$ is large, shielding occurs for the higher cloud $(5 \mathrm{~km})$ at relatively low optical thicknesses $(\tau>\sim 0.5)$. For the nadir view, the same magnitude of shielding occurs for $\tau>\sim 2.5$. This viewing geometry dependence is even larger for cloud height $3 \mathrm{~km}$, with $\Delta P$ reaching the $100 \mathrm{hPa}$ threshold at $\tau \simeq 1$ and 7 at the swath edge and nadir, respectively.

The $\tau$ at which $\Delta P$ is equal to $100 \mathrm{hPa}\left(\tau_{100}\right)$, depends on surface albedo $A$. For $A=0.9, \tau_{100}$ for nadir observations is 


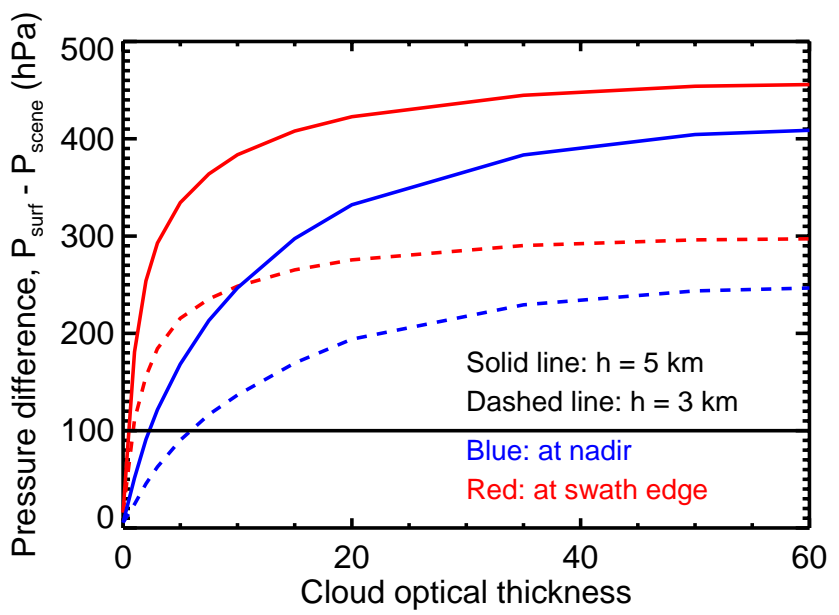

Fig. 2. Cloud pressure difference, $P_{\text {surf }}-P_{\text {scene, from simulated ice }}$ cloud data for surface albedo 0.7 and geometry of OMI scan line 300 .

higher by a factor of 2.5-3.0 compared with that at $A=0.7$. This factor is approximately the same for all three cloud models. The choice of phase function has a substantial effect on the absolute value of $\tau_{100}$. This effect is most pronounced for nadir observations and is generally small at swath edge. Simulations show that the smallest and largest values of $\tau_{100}$ occur for the $\mathrm{H}-\mathrm{G}$ phase and $\mathrm{C} 1$ phase functions, respectively. For instance, $\tau_{100}=0.5,2.5$, and 7 for the H-G, ice crystal, and $\mathrm{C} 1$ phase functions, respectively for $A=0.7$ and cloud top height $5 \mathrm{~km}$.

Figure 3 shows the difference between the cloud top pressure and retrieved scene pressure. The scene pressure rapidly approaches the cloud top pressure at swath edge. As expected, nadir observations have more sensitivity deeper inside the cloud.

\subsection{Sensitivity of TOA radiance to ozone absorption beneath clouds}

In the second series of RT simulations, we used cloud extinction profiles from CloudSat over Antarctica. The Cloud Profiling Radar (CPR) on CloudSat provides information about cloud vertical structure over snow and ice (Stephens et al., 2002). The CPR generates 2-D radar reflectivity cross sections through clouds. The combination of information from CPR and MODIS yields estimates of vertical optical extinction profiles and total $\tau$ of clouds (Stephens et al., 2008).

Figure 4 shows probability density functions of the total cloud $\tau$ over Antarctica and the surrounding sea ice for 13 November 2006. Over sea ice, the distribution is bimodal with a large narrow spike at low optical thicknesses $(<3)$ and a broad secondary peak near $\tau=20$. There are more thin clouds over the continent with a broad tail at higher optical thicknesses and no distinct secondary mode. Figure 4 also shows average profiles of cloud extinction for three bins:

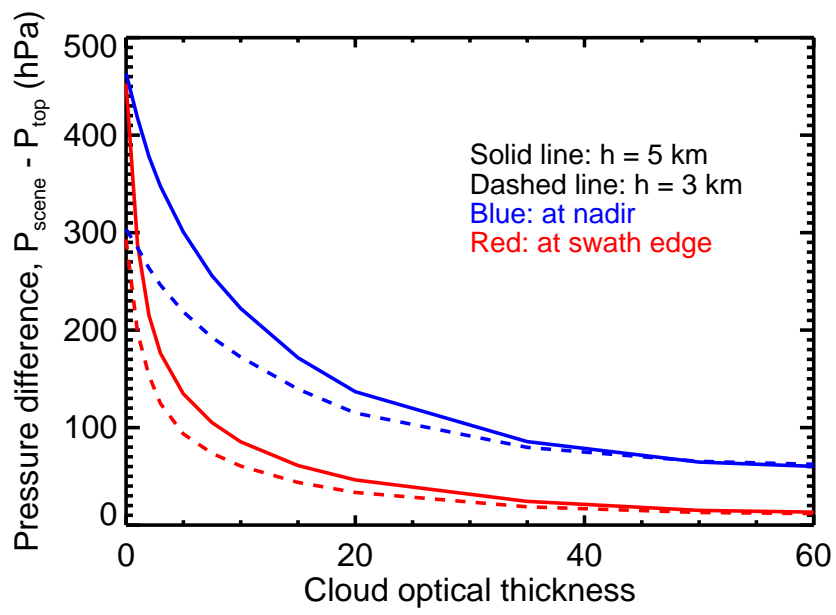

Fig. 3. As in Fig. 2 but for cloud-top pressure difference, $P_{\text {scene }}-$ $P_{\text {top. }}$

Table 1. Latitude (Lat.), longitude (Long.), solar zenith angle $\left(\theta_{0}\right)$, viewing zenith angle $(\theta)$, relative azimuth angle $(\phi)$, and total cloud optical thickness $(\tau)$ of CloudSat profiles used for Jacobian computations.

\begin{tabular}{crrrrrr}
\hline Profile \# & Lat. & Long. & $\theta_{0}$ & $\Theta$ & $\phi$ & $\tau$ \\
\hline 1 & -68.76 & -29.41 & 61.05 & 11.22 & 127.36 & 5.6 \\
2 & -63.96 & -89.45 & 57.18 & 15.49 & 129.95 & 22.8 \\
3 & -70.36 & -139.83 & 62.46 & 11.22 & 126.65 & 15.6 \\
4 & -68.59 & -29.41 & 60.83 & 11.22 & 127.36 & 33.7 \\
\hline
\end{tabular}

$0<\tau<5,5<\tau<25$, and $\tau>25$. Over sea ice, there is a predominant peak in optical thickness at about $1 \mathrm{~km}$ altitude for moderate to high optical thickness clouds. Over land, the optical depth peaks at higher altitudes $(\sim 5 \mathrm{~km})$.

To study how clouds over snow and ice affect the sensitivity of TOA radiances, $I$, to tropospheric ozone absorption, we compute Jacobians $\partial \ln I / \partial \tau(h)$, where $\tau(h)$ is the ozone optical depth in a $1 \mathrm{~km}$ layer as a function of altitude $h$. We select four typical profiles of cloud extinction derived from CloudSat/MODIS over snow/ice: one for optically thin cloud, the second for a distinct two layer cloud scenario, thirdly for a high-altitude optically thick cloud, and finally for a low-altitude optically thick cloud. We use the solar and viewing conditions for OMI pixels collocated with the CloudSat/MODIS retrievals (see Table 1 for details).

Figures 5 and 6 compare Jacobians computed for clearsky and cloudy conditions. The Jacobians were computed with the $\mathrm{C} 1$ cloud model and for surface albedos of 0.7 and 0.9. The total ozone amount was set to $235 \mathrm{DU}$ with the tropospheric ozone mixing ratio approximately constant $(\sim 0.04 \mathrm{ppmv})$ below $10 \mathrm{~km}$. The choice of phase function had a negligible effect on the Jacobians for these cases. 

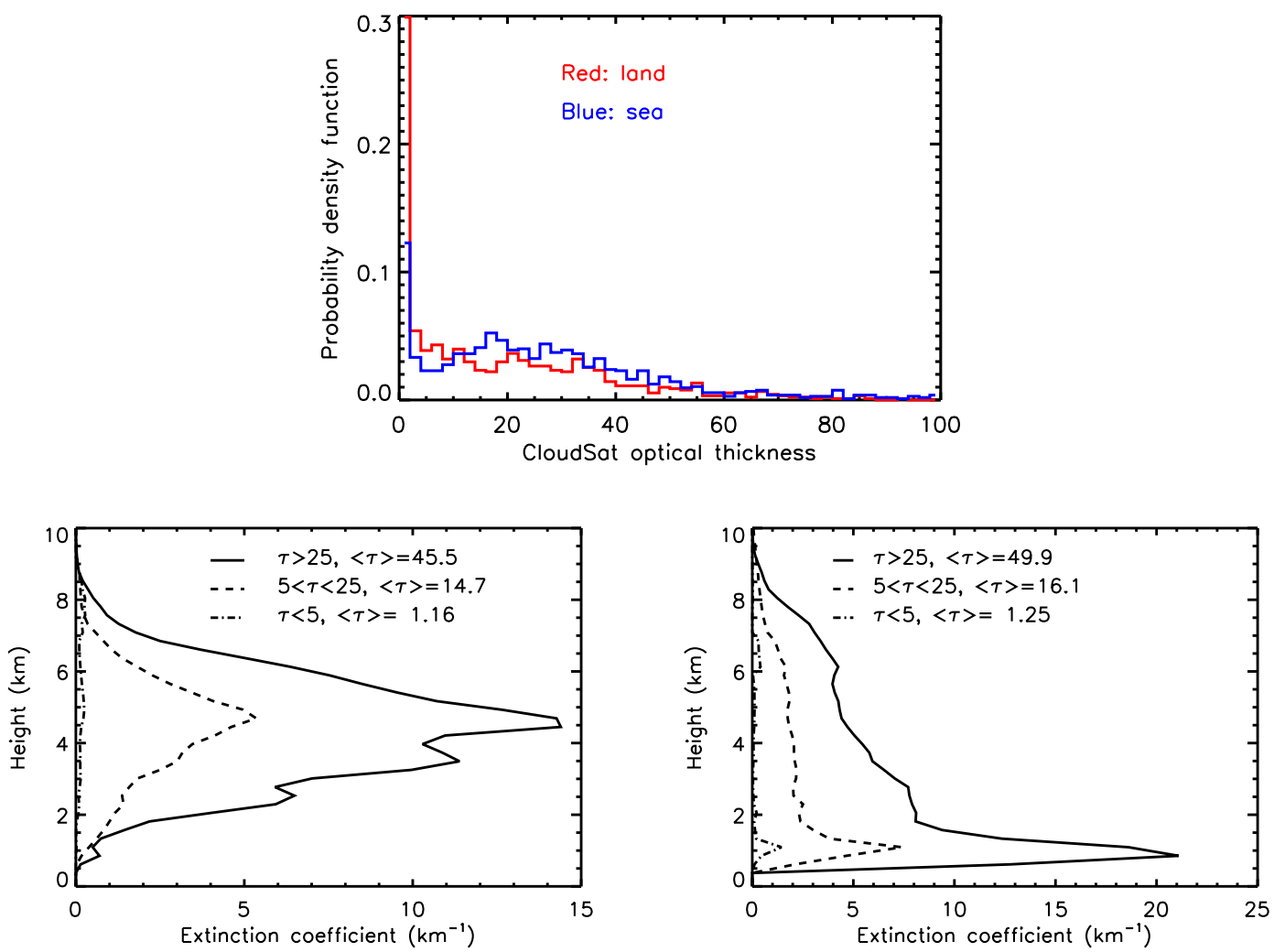

Fig. 4. Top: probability density function of cloud optical thickness for cloudy data over Antarctica and surrounding sea ice on 13 November 2006. Bottom: average profiles of cloud extinction for three $\tau$ bins and latitudes $<-60^{\circ}$. Left: land; right: sea.

As seen in Figs. 5 and 6, there is enhanced ozone absorption above the clouds. This enhanced absorption above clouds is less pronounced for higher surface albedos. For the two layer cloud, ozone absorption is enhanced above both the upper and lower cloud layers. The difference between clear and cloudy sky Jacobians below clouds can be interpreted as the cloud shielding effect. The amount of cloud shielding depends on $\tau$ and the cloud vertical structure; optically thick clouds lead to greater shielding sensitivity, while cloud vertical structure determines the onset of shielding. The amount of cloud shielding is reduced at higher surface albedo.

\section{Cloud classification over snow/ice with OMI and MODIS}

Here we perform a simple classification of clouds over snow and ice surfaces without the benefit of the MODIS nearIR channel for which snow and ice surfaces appear dark. The classification scheme makes use of the pressure difference $\Delta P=P_{\text {surf }}-P_{\text {scene }}$ between the surface and the derived scene pressures. It also uses the cloud top pressure $P_{\text {top }}$ (expressed as a fraction of the troposphere), i.e., $\bar{P}_{\text {top }}=$ $\left(P_{\text {surf }}-P_{\text {top }}\right) /\left(P_{\text {surf }}-P_{\text {tropo }}\right)$, where $P_{\text {tropo }}$ is the tropopause pressure. A latitude-dependent estimate of the tropopause pressure is provided in the MODIS data set.

The classification proceeds as follows: If $\bar{P}_{\text {top }}>0.3$, clouds are considered to be reliably detected. For detected clouds, if $\Delta P>100 \mathrm{hPa}$, clouds are designated as shielding, otherwise they are classified as non-shielding. As expected, for all reliably detected clouds, the derived scene pressure was greater than the cloud top pressure.

Figures 7 and 8 show results of the classification over Antarctica for OMI orbits 12394 and 12395, respectively on 13 November 2006. The cloud classification looks qualitatively similar to a map of cloud optical thickness retrieved from MODIS for that day (not shown); shielding clouds occur where cloud optical thickness is high and non-shielding clouds are present at lower cloud optical thicknesses. To evaluate this scheme in more detail, we use collocated CloudSat data.

Figure 9 shows cloud optical extinction from the CloudSat/MODIS 2B-Tau product (Stephens et al., 2008) along the orbital track shown in Fig. 7 (OMI orbit 12394). Figure 9 also shows OMI scene pressures, MODIS minimum cloud top pressure within that OMI scene, and surface pressures. OMI scene and surface pressures are very similar for latitudes south of $-67^{\circ}$. The absence of clouds for those 

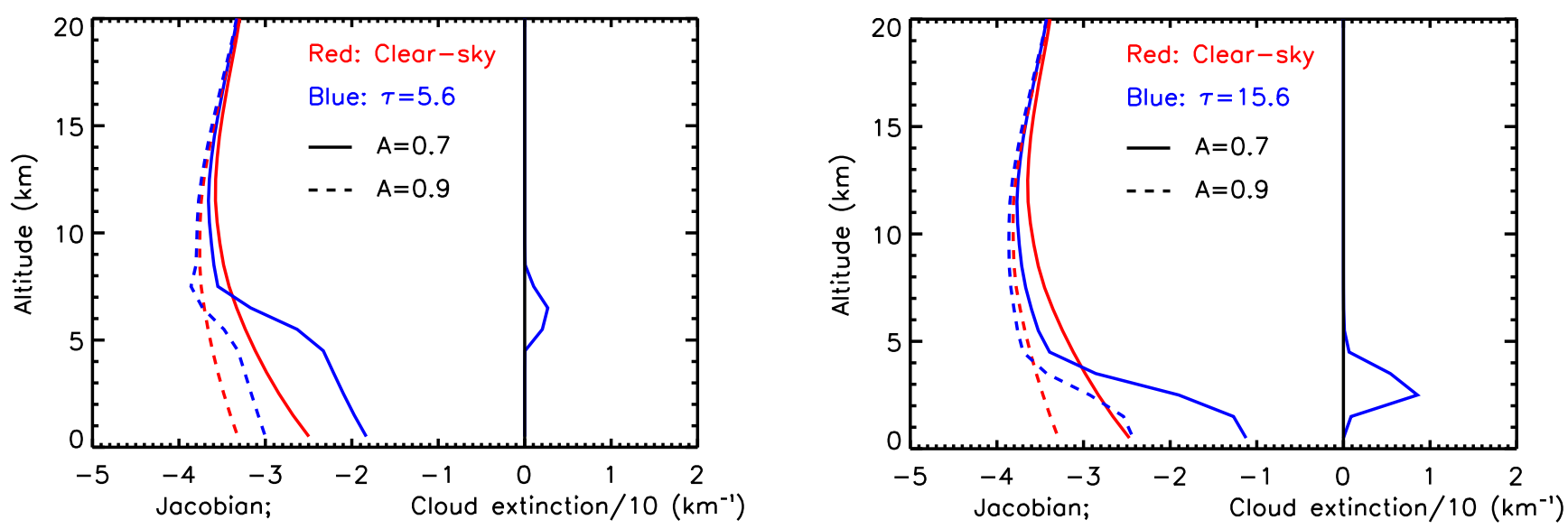

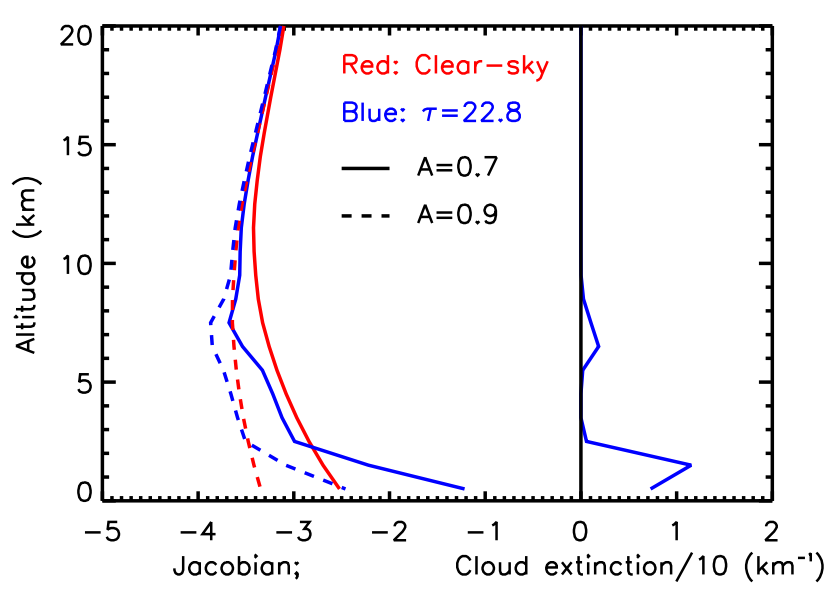

Fig. 5. Jacobians (derivative of natural $\log$ of radiance with respect to the ozone optical depth) (left) computed for two different (top and bottom) CloudSat/MODIS cloud extinction profiles (right) and two values of surface albedos $A$.

latitudes is confirmed by CloudSat. Surface pressures are provided at $0.5^{\circ} \times 0.5^{\circ}$ resolution, which is coarser than the near-nadir OMI spatial resolution. This discrepancy is responsible for some of the differences between surface and OMI scene pressures. For latitudes between $-67^{\circ}$ and $-66^{\circ}$, OMI-retrieved scene pressures are slightly less than surface pressures, and MODIS observes high clouds. These pixels are classified as non-shielding clouds. In contrast, OMI scene pressures for latitudes north $-66^{\circ}$ are much lower than corresponding surface pressures, and MODIS again observes high clouds. The shielding classification coincides with geometrically and optically thick clouds observed by CloudSat/MODIS.

Another example of validation of our cloud classification scheme with Cloudsat/MODIS data is shown in Fig. 10 for OMI orbit 12395. Again, CloudSat confirms the absence of clouds for latitudes south of $-70^{\circ}$ where OMI scene pressures are close to surface pressures. There are two regions:

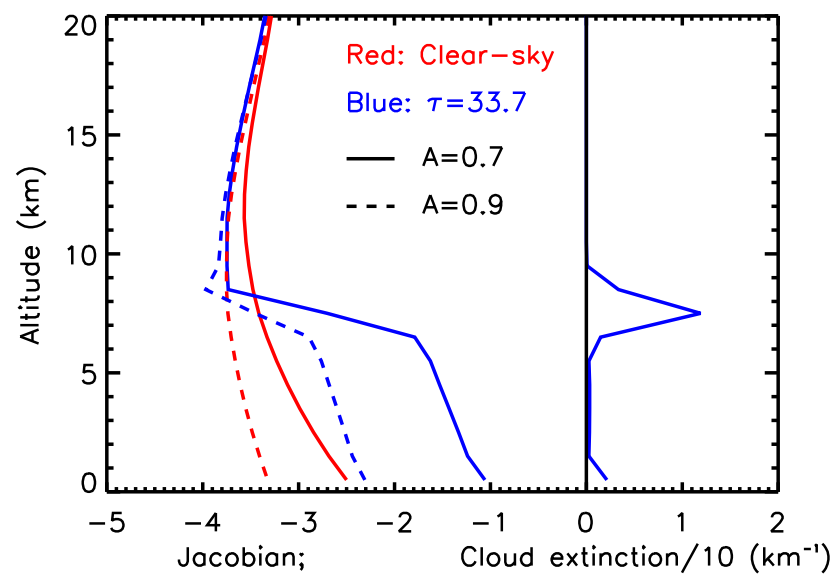

Fig. 6. Similar to Fig. 5 for different cloud extinction profiles.

between $-70^{\circ}$ and $-71^{\circ}$ and $-61^{\circ}$ and $-60^{\circ}$, where MODIS observes high clouds and OMI scene pressures are somewhat less than surface pressures. Those regions are classified as non-shielding clouds and CloudSat/MODIS confirms that clouds have moderate optical depths there. The regions with optically thick clouds observed by CloudSat/MODIS are correctly classified as shielding clouds.

CloudSat has a narrow field-of-view $(\sim 1.4 \mathrm{~km})$ as compared with the cross-track size of an OMI pixel (minimum of $24 \mathrm{~km}$ ). Therefore, clouds seen in the thin CloudSat slice through an OMI pixel may not be representative of the cloud conditions for that pixel, especially when there is significant spatial inhomogeneity. Despite this, our comparisons with CloudSat data show that the OMI/MODIS classification scheme provides reasonable results in most of the examined cases. 


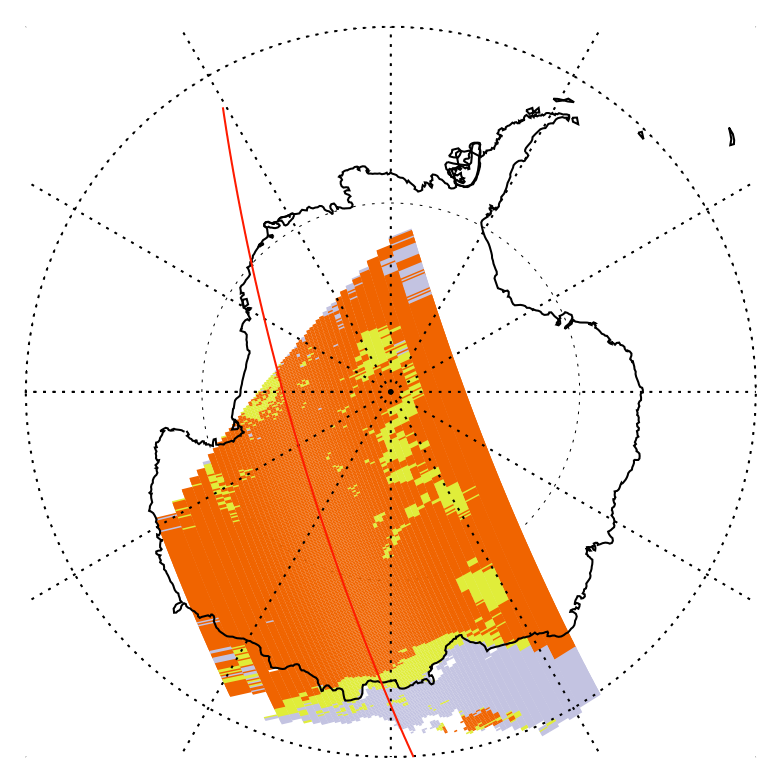

Fig. 7. Map of cloud classification over Antarctica for OMI orbit 12394: not detectable or no clouds in orange, non-shielding (optically thin) clouds in yellow, and shielding (optically thick) clouds in light blue/gray. The red line represents the collocated CloudSat orbital track.

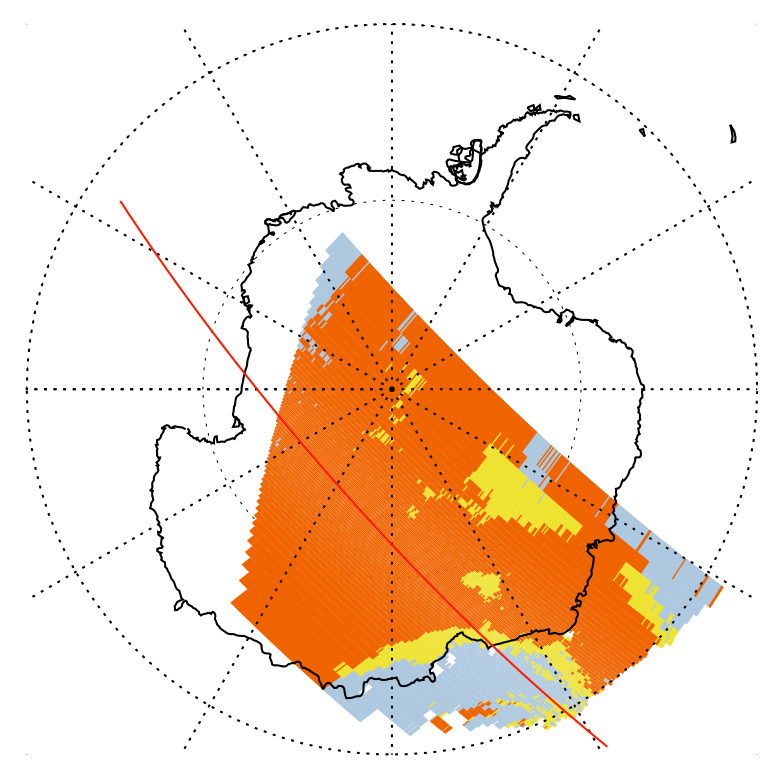

Fig. 8. As in Fig. 7 but for OMI orbit 12395.

\section{Total column ozone retrievals over snow and ice}

Over snow and ice, the current TOMS algorithm (version 8.5 or V8.5, also known as OMTO3 when applied to OMI) retrieves ozone column amounts assuming no clouds. It was shown in Sect. 3.2 that clouds can substantially shield the satellite measurements from ozone beneath them. It follows that the no-cloud OMTO3 assumption over snow and ice

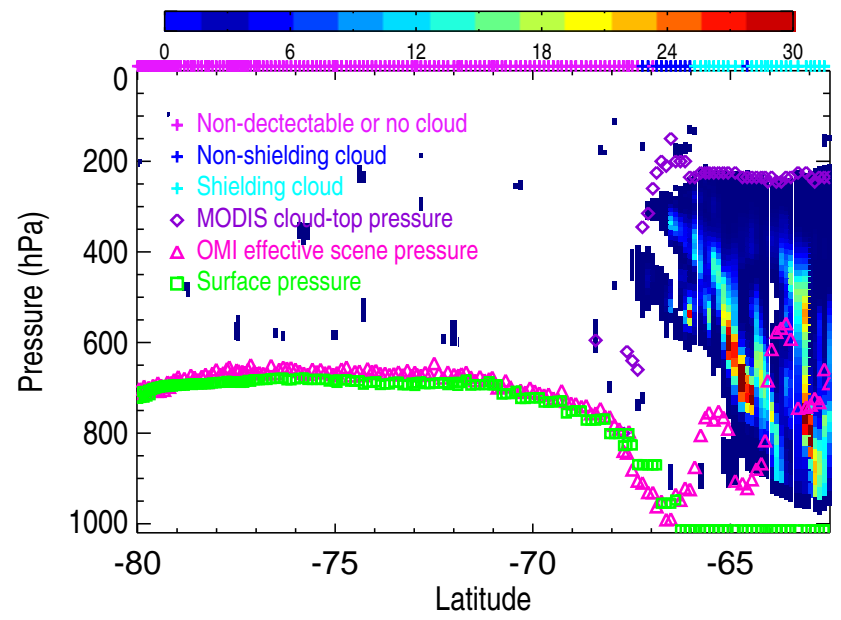

Fig. 9. CloudSat cross section of cloud extinction (upper color scale in $\mathrm{km}^{-1}$ ) with various parameters retrieved from collocated OMI and MODIS data for OMI orbit 12394 on 13 November 2006. Results of the cloud classification are shown on the upper $\mathrm{x}$-axis.

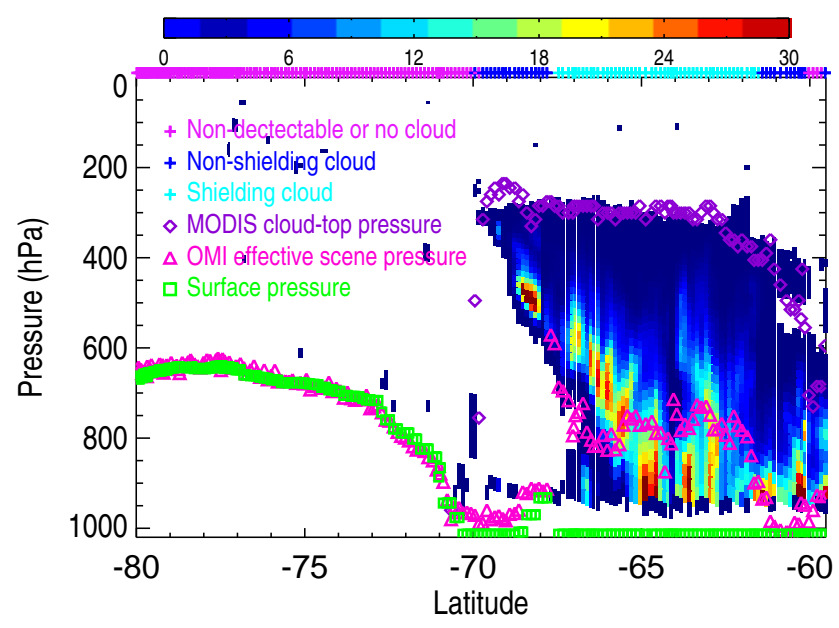

Fig. 10. As in Fig. 9 but for OMI orbit 12395.

tends to underestimate retrieved total column ozone, because the shielded amount is not accounted for. As discussed in Joiner et al. (2006), the assumed cloud pressure can impact the total ozone retrieval in several other ways. These include estimation of the multiple scattering between the cloud and overlaying atmosphere and the effects of rotational-Raman scattering on TOA radiances. In many cases, these effects can be in the same direction as the cloud shielding effect and therefore may further increase the total ozone error. Use of OMI scene pressures in the OMTO3 algorithm should reduce these sources of ozone retrieval error.

Figure 11 shows total column ozone differences, $\Delta \Omega$, resulting from the use of OMI scene pressures as compared with the OMTO3 V8.5 algorithm that assumes no clouds over snow and ice for orbit 12394 on 13 November 2006. 


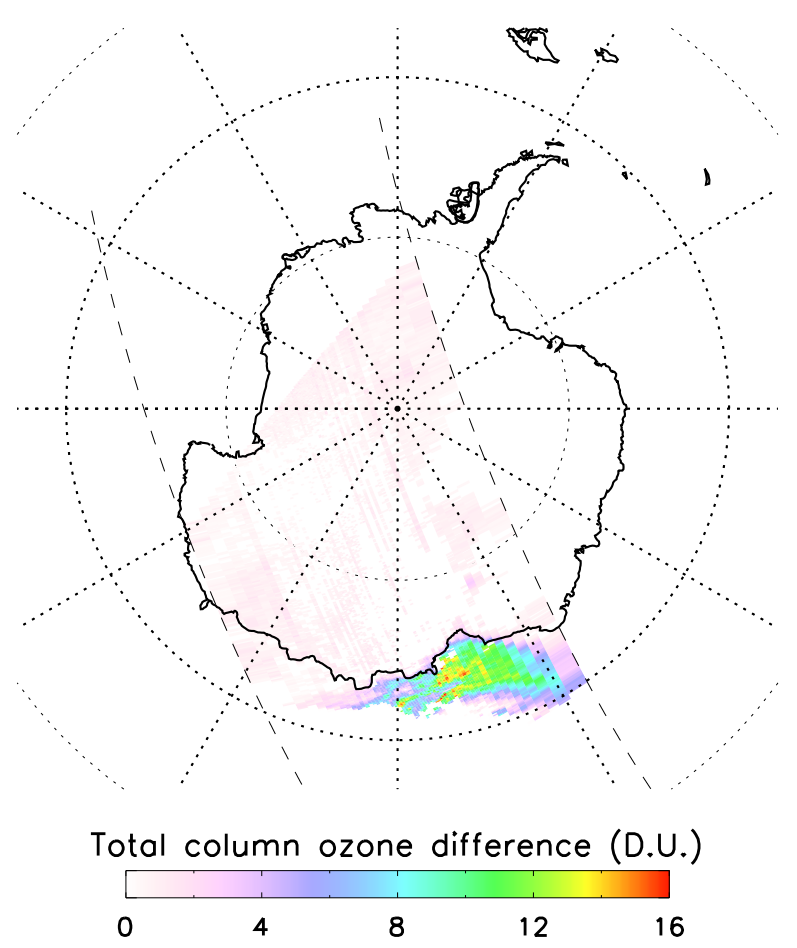

Fig. 11. Column ozone difference between the retrievals with OMIderived scene pressures and those from the OMTO3 V8.5 algorithm for OMI orbit 12394.

Only data for $\theta<80^{\circ}$ and $\Delta P>25 \mathrm{hPa}$ are shown. For reference, Fig. 12 shows a map of OMTO3 V8.5 total ozone for the same orbit.

As expected areas with the largest differences correspond to those with shielding clouds. $\Delta \Omega$ incorporates all of the above-described cloud effects on the ozone retrieval. $\Delta \Omega$ is mostly $<12$ Dobson Units (DU), but can be as large as $\sim 15$ DU. About half of this difference comes from the hidden ozone (below the cloud). The mean $\Delta \Omega$ for this orbit is $2.5 \mathrm{DU}$ (or approximately $1.5 \%$ ), with a standard deviation of 3.4 DU. The mean $\Delta \Omega$ and standard deviation somewhat vary from orbit to orbit. For instance, the mean $\Delta \Omega$ is $2.1 \mathrm{DU}$ and the standard deviation is $2.1 \mathrm{DU}$ for adjacent OMI orbit 13295.

Vasilkov et al. (2004) showed that use of retrieved cloud pressures in place of cloud climatology leads to a smoother spatial distribution of total column ozone. Spatial irregularities are presumably caused by the differences between the retrieved and climatological cloud pressures. In Fig. 13 for one OMI scan line, we compare spatial distributions of total column ozone retrieved with and without OMI scene pressures. The comparison shows the expected smoother spatial distribution of ozone retrieved with OMI scene pressures; smallscale unphysical irregularities in the standard ozone spatial distribution are reduced.

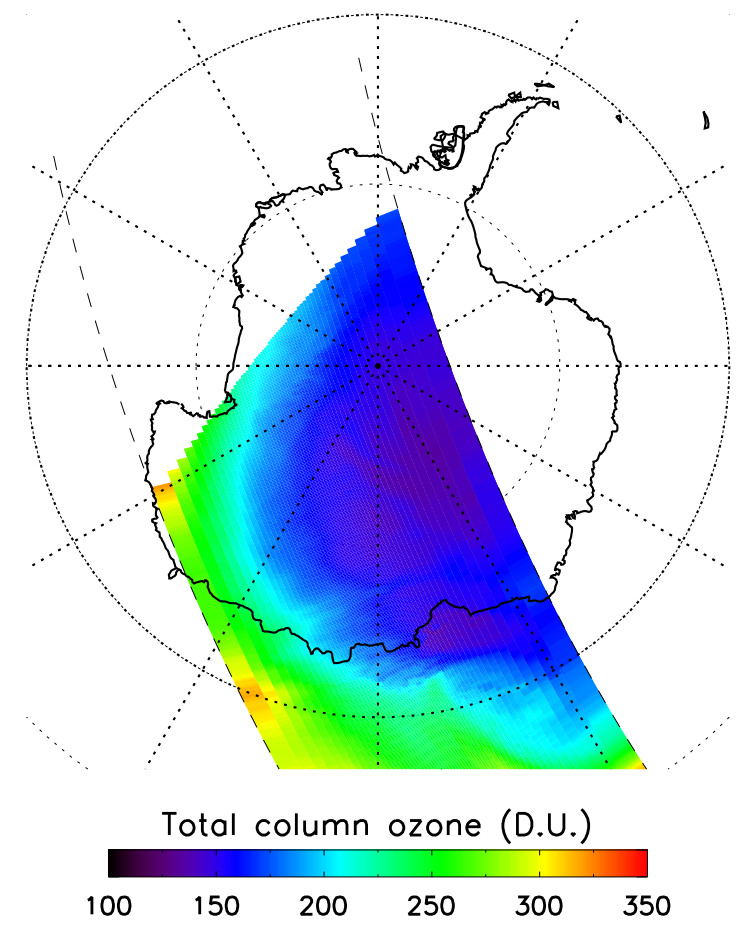

Fig. 12. OMTO3 V8.5 total column ozone retrieved for OMI orbit 12394 .

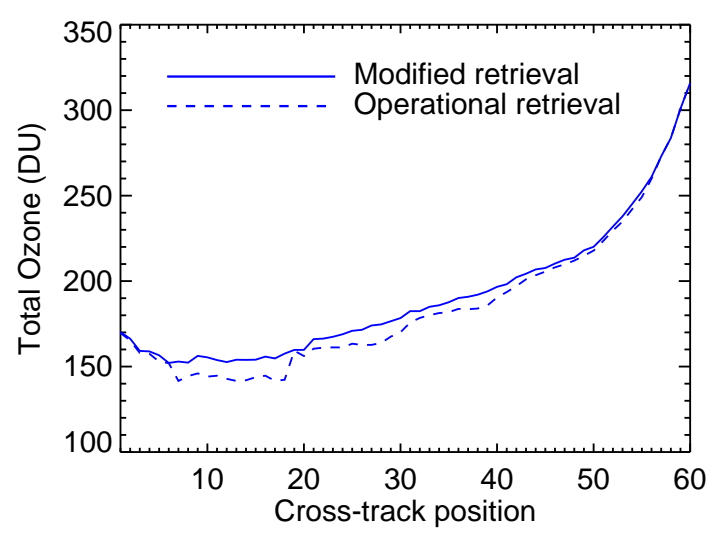

Fig. 13. Total column ozone retrieved with OMI scene pressures (modified) and those retrieved with the no-cloud assumption over snow and ice (operational) along OMI scan line 400 as a function of OMI cross-track position.

\section{Conclusions}

Clouds over snow and ice surfaces can produce significant shielding of tropospheric ozone absorption. Shielding clouds can be detected by means of differences between OMIderived scene and surface pressures. A combination of the OMI effective scene pressure and the MODIS cloud-top pressure allows us to distinguish between shielding and nonshielding clouds. 
The no-cloud over snow/ice assumption in the current OMTO3 algorithm underestimates total ozone by an average of approximately 2-3 DU under cloudy conditions, with a maximum error as large as $15 \mathrm{DU}$. Use of OMI-retrieved scene pressures in OMTO3 reduces this error and leads to a more homogeneous spatial distribution of total column ozone.

The next version of OMTO3 will use OMI-derived scene pressures over snow and ice. For the reprocessing of historic TOMS data (for which concurrent scene pressures are not available), we plan to use a new climatology of OMI-derived scene pressures over snow and ice.

The historical TOMS wavelengths are significantly affected by the Ring effect (Joiner et al., 2006). For continuity, the same wavelengths are currently used in the OMI-TOMS algorithm. Because OMI has higher spectral resolution, the Ring effect is even larger in OMI channels than in the corresponding TOMS channels. As a result, the OMI-TOMS total ozone retrieval has a large sensitivity to cloud vertical structure. In order to reduce this sensitivity, slight changes to the OMI-TOMS wavelengths are being considered for future versions that will be used to reprocess the OMI data.

While it is possible to derive information about cloud pressure from the limited number of available TOMS and SBUV discrete wavelengths (Joiner and Bhartia, 1995), the subsequent errors are comparable to or greater than those resulting from the use of a cloud climatology produced from OMI. In future reprocessing of historical TOMS and SBUV data, the current infrared-based cloud climatology will be replaced with one produced from OMI data. This will reduce systematic errors in the estimated total ozone over all surface types.

Acknowledgements. The authors thank the OMI, MODIS, and CloudSat science teams for the processing and distribution of data sets used here. This material is based upon work supported by the National Aeronautics and Space Administration under agreement NNG06HX18C issued through the Science Mission Directorate for the Aura Science Team.

Edited by: C. von Savigny

\section{References}

Ackerman, S. A., Strabala, K. I., Menzel, W. P., Frey, R. A., Moeller, C. C., and Gumley, L. E.: Discriminating clear sky from clouds with MODIS, J. Geophys. Res., 103, 32141-32157, 1998.

Ackerman, S. A., Strabala, K. I., Menzel, W. P., Frey, R. A., Moeller, C. C., Gumley, L. E., Baum, B., Seeman, S. W., and Zhang, H.: Discriminating clear sky from clouds with MODIS, ATBD-MOD-06, available at: http://modis-atmos.gsfc.nasa.gov/ MOD35_L2/atbd.html, 2006.

Baum, B. A., Yang, P., Heymsfield, A. J., Platnick, S., King, M. D., $\mathrm{Hu}$, Y. X., and Bedka, S. T.: Bulk scattering models for the remote sensing of ice clouds. Part 2: Narrowband models, J. Appl. Meteorol., 44, 1896-1911, 2005.
Bhartia, P. K. and Wellemeyer, C. W.: TOMS-V8 Total O3 Algorithm, OMI Algorithm Theoretical Basis Document, vol. 2, edited by: Bhartia, P. K., Greenbelt, MD, available at: http: /toms.gsfc.nasa.gov/version8/v8toms_atbd.pdf, 2002.

Bovensmann, H., Burrows, J., Buchwitz, M., Frerick, J., Noel, S., Rozanov, V., Chance, K., and Goede, A.: SCIAMACHY: mission objectives and measurement modes, J. Atmos. Sci., 56, 127-150, 1999.

Burrows, J. P., Weber, M., Buchwitz, M., Rozanov, V., LadstätterWeißenmayer, A., Richter, A., DeBeek, R., Hoogen, R., Bramstedt, K., Eichmann, K.-U., and Eisinger, M.: The Global Ozone Monitoring Experiment (GOME): Mission concept and first scientific results, J. Atmos. Sci., 56, 151-175, 1999.

Coldewey-Egbers, M., Weber, M., Lamsal, L. N., de Beek, R., Buchwitz, M., and Burrows, J. P.: Total ozone retrieval from GOME UV spectral data using the weighting function DOAS approach, Atmos. Chem. Phys., 5, 1015-1025, doi:10.5194/acp5-1015-2005, 2005.

Curry, J. A., Rossow, W. B., Randall, D., and Schramm, J. L.: Overview of arctic cloud and radiation characteristics, J. Climate, 9, 1731-1764, 1996.

Deirmendjian, D.: Electromagnetic scattering on spherical polydispersions, Elsevir Sci., New York, 290 pp., 1969.

Gao, B.-C., Han, W., Tsay, S. C., and Larsen, N. F.: Cloud detection over the Arctic region using airborne imaging spectrometer data during the daytime, J. Appl. Meteorol., 37, 1421-1429, 1998.

Joiner J., and Bhartia, P. K.: Accurate Determination of Total Ozone using SBUV Continuous Spectral Scan Measurements, J. Geophys. Res., 102, 12957-12969, 1995.

Joiner, J., Vasilkov, A. P., Flittner, D. E., Gleason, J. F., and Bhartia, P. K.: Retrieval of cloud pressure and oceanic chlorophyll content using Raman scattering in GOME ultraviolet spectra, J. Geophys. Res., 109, D01109, doi:10.1029/2003JD003698, 2004.

Joiner, J. and Vasilkov, A. P.: First results from the OMI rotational raman scattering cloud pressure algorithm, IEEE T. Geosci. Remote, 44, 1272-1282, 2006.

Joiner, J., Vasilkov, A. P., Yang, K. and Bhartia, P. K.: Total column ozone over hurricanes from the ozone monitoring instrument, Geophys. Res. Lett., 33, L06807, doi:10.1029/2005GL0255922006, 2006.

Joiner, J., Schoeberl, M. R., Vasilkov, A. P., Oreopoulos, L., Platnick, S., Livesey, N. J., and Levelt, P. F.: Accurate satellitederived estimates of the tropospheric ozone impact on the global radiation budget, Atmos. Chem. Phys., 9, 4447-4465, doi:10.5194/acp-9-4447-2009, 2009.

Joiner, J., Vasilkov, A. P., Bhartia, P. K., Wind, G., Platnick, S., and Menzel, W. P.: Detection of multi-layer and vertically-extended clouds using A-train sensors, Atmos. Meas. Tech., 3, 233-247, doi:10.5194/amt-3-233-2010, 2010.

Key, J.: The cloud and surface parameter retrieval (CASPR) system for polar AVHRR, Cooperative Institute for Meteorological Satellite Studies, University of Wisconsin, Madison, available at: http://stratus.ssec.wisc.edu/caspr, 2002.

Key, J. R., Wang, X., Stoeve, J. C., and Fowler, C.: Estimating the cloudy-sky albedo of sea ice and snow from space, J. Geophys. Res., 106, 12489-12497, 2001.

Khlopenkov, K. V. and Trishchenko, A. P.: SPARC: New cloud, snow, and cloud shadow detection scheme for historical $1-\mathrm{km}$ 
AVHRR data over Canada, J. Atmos. Ocean. Tech., 24, 322-343, 2007.

Krijger, J. M., Aben, I., and Schrijver, H.: Distinction between clouds and ice/snow covered surfaces in the identification of cloud-free observations using SCIAMACHY PMDs, Atmos. Chem. Phys., 5, 2729-2738, doi:10.5194/acp-5-2729-2005, 2005.

Koelemeijer, R. B. A. and Stammes, P.: Effects of clouds on ozone column retrieval from GOME UV measurements, J. Geophys. Res., 104, 8281-8294, 1999.

Koelemeijer, R. B. A., Stammes, P., Hovenier, J. W., and de Haan, J. F.: A fast method for retrieval of cloud parameters using oxygen A-band measurements from the Global Ozone Monitoring Experiment, J. Geophys. Res., 106, 3475-3496, 2001.

Kokhanovsky, A. A., Rozanov, V. V., Nauss, T., Reudenbach, C., Daniel, J. S., Miller, H. L., and Burrows, J. P.: The semianalytical cloud retrieval algorithm for SCIAMACHY I. The validation, Atmos. Chem. Phys., 6, 1905-1911, doi:10.5194/acp-6-1905-2006, 2006.

Levelt, P. F., van der Oord, G. H. J., Dobber, M. R., et al.: The ozone monitoring instrument, IEEE T. Geosci. Remote, 44, 1093-1101, 2006.

Li, W., Stamnes, K., Eide, H., and Spurr, R.: Bidirectional Reflectance Distribution Function (BRDF) of snow: correction for the Lambertian assumption in remote sensing applications, Opt. Eng., 46, 1-9, 2007.

Li, X., Pinker, R. T., Wonsick, M. M., and Ma, Y.: Toward improved satellite estimates of short-wave radiative fluxes - focus on cloud detection over snow: 1. Methodology, J. Geophys. Res., 112, D07208, doi:10.1029/2005JD006698, 2007.

Lotz, W. A., Vountas, M., Dinter, T., and Burrows, J. P.: Cloud and surface classification using SCIAMACHY polarization measurement devices, Atmos. Chem. Phys., 9, 1279-1288, doi:10.5194/acp-9-1279-2009, 2009.

Michelangeli, D. V., Allen, M., Yung, Y. L., Shia, R.-L., Crisp, D., and Eluszkiewicz, J.: Enhancement of atmospheric radiation by an aerosol layer, J. Geophys. Res., 97, 865-874, 1992.

Munro, R., Eisinger, M., Anderson, C., Callies, J., Corpaccioli, E., Lang, R., Lefebvre, A., Livschitz, Y., and Perez Albinana, A.: GOME-2 on Metop: from in-orbit verification to routine operations, in: Proceedings of EUMETSAT Meteorological Satellite Conference, Helsinki, Finland, 12-16 June 2006.

Nolin, A., Armstrong, R. L., and Maslanik, J.: Near Real-Time SSM/I EASE-Grid Daily Global Ice Concentration and Snow Extent, Jan to Mar 2004 (updated daily), Boulder, CO, USA: National Snow and Ice Data Center, Digital media, 1998.

Pinker, R. T., Li, X., Meng, W., and Egorova, E. A.: Toward improved satellite estimates of short-wave radiative fluxes - focus on cloud detection over snow: 2. Results, J. Geophys. Res., 112, D09204, doi:10.1029/2005JD006699, 2007.

Platnick, S., Li, J. Y., King, M. D., Gerber, H., and Hobbs, P. V.: A solar reflectance method for retrieving the optical thickness and droplet size of liquid water clouds over snow and ice surfaces, J. Geophys. Res., 106, 15185-15199, 2001.

Roozendael van, M., Loyola, D., Spurr, R., Balis, D., Lambert, J.-C., Livschitz, Y., Valks, P., Ruppert, T., Kenter, P., Fayt, C., and Zehner, C.: Ten years of GOME/ERS-2 total ozone data - The new GOME data processor (GDP) version 4: 1. Algorithm description, J. Geophys. Res., 111, D14311,
doi:10.1029/2005JD006375, 2006.

Rozanov, V. V. and Kokhanovsky, A. A.: Semianalytical cloud retrieval algorithm as applied to the cloud top altitude and the cloud geometrical thickness determination from top-of-atmosphere reflectance measurements in the oxygen A band, J. Geophys. Res., 109, D05202, doi:10.1029/2003JD004104, 2004.

Rozanov, V. V., Kokhanovsky, A. A., and Burrows, J. P.: The determination of cloud altitudes using GOME reflectance spectra: multilayered cloud systems, IEEE T. Geosci. Remote, 42, 10091017, 2004.

Sneep, M., De Haan, J., Stammes, P., Wang, P., Vanbauce, C., Joiner, J., Vasilkov, A. P., and Levelt, P. F.: Three way comparison between OMI/Aura and POLDER/PARASOL cloud pressure products, J. Geophys. Res., 113, D15S23, doi:10.1029/2007JD008694, 2008.

Spurr, R. J. D., de Haan, J., van Oss, R., and Vasilkov, A. P.: Discrete ordinate radiative transfer in a stratified medium with first order rotational Raman scattering, J. Quant. Spectrosc. Ra., 109(3), 404-425, 2008.

Stephens, G. L., Vane, D. G., Boain, R. J., Mace,G. G., Sassen, K., Wang, Z., Illingworth, A. J., O’Connor, E. J., Rossow, W. B., Durden, S. L., Miller, S. D., Austin, R. T., Benedetti, A., Mitrescu, C., and The CloudSat Science Team: The CloudSat mission and the A-Train: a new dimension of space-based observations of clouds and precipitation, B. Am. Meteorol. Soc., 83, 1771-1790, 2002.

Stephens, G. L., Vane, D. G., Tanelli, S., Im, E., Durden, S., Rokey, M., Reike, D., Partain, P., Mace, G. G., Austin, R., L'Ecuyer, T., Haynes, J., Lebsock, M., Suzuki, K., Waliser, D., Wu, D., Kay, J., Gettelman, A., Wang, Z., and Marchands, R.: CloudSat mission: performance and early science after the first year of operations, J. Geophys. Res., 113, D00A18, doi:10.1029/2008JD009982, 2008.

Vasilkov, A. P., Joiner, J., Yang, K., and Bhartia, P. K.: Improving total column ozone retrievals by using cloud pressures derived from Raman scattering in the UV, Geophys. Res. Lett., 31, L20109, doi:10.1029/2004GL020603, 2004.

Vasilkov, A. P., Joiner, J., Spurr, R., Bhartia, P. K., Levelt, P. F., and Stephens, G.: Evaluation of the OMI cloud pressures derived from rotational Raman scattering by comparisons with other satellite data and radiative transfer simulations, J. Geophys. Res., 113, D15S19, doi:10.1029/2007JD008689, 2008.

Vasilkov, A. P., Joiner, J., Oreopoulos, L., Gleason, J. F., Veefkind, P., Bucsela, E., Celarier, E. A., Spurr, R. J. D., and Platnick, S.: Impact of tropospheric nitrogen dioxide on the regional radiation budget, Atmos. Chem. Phys., 9, 6389-6400, doi:10.5194/acp-96389-2009, 2009.

Wang, X. and Key, J. R.: Recent trends in Arctic surface, cloud, and radiation properties from space, Science, 299, 1725-1728, 2003.

Ziemke, J. R., Joiner, J., Chandra, S., Bhartia, P. K., Vasilkov, A., Haffner, D. P., Yang, K., Schoeberl, M. R., Froidevaux, L., and Levelt, P. F.: Ozone mixing ratios inside tropical deep convective clouds from OMI satellite measurements, Atmos. Chem. Phys., 9, 573-583, doi:10.5194/acp-9-573-2009, 2009. 